\title{
SIDE GROUP ADDITION TO THE POLYCYCLIC AROMATIC HYDROCARBON CORONENE BY ULTRAVIOLET PHOTOLYSIS IN COSMIC ICE ANALOGS
}

\author{
Max P. Bernstein, ${ }^{1,2}$ Jamie E. Elsila, ${ }^{3}$ Jason P. Dworkin, ${ }^{1,2}$ Scott A. Sandford, ${ }^{1}$ \\ Louis J. Allamandola, ${ }^{1}$ AND Richard N. ZarE ${ }^{3}$ \\ Received 2002 February 23; accepted 2002 May 18
}

\begin{abstract}
Ultraviolet photolysis of various coronene-ice mixtures at low temperature and pressure caused the addition of amino $\left(-\mathrm{NH}_{2}\right)$, methyl $\left(-\mathrm{CH}_{3}\right)$, methoxy $\left(-\mathrm{OCH}_{3}\right)$, cyano/isocyano $(-\mathrm{CN},-\mathrm{NC})$, and acid $(-\mathrm{COOH})$ functional groups to the polycyclic aromatic hydrocarbon $(\mathrm{PAH})$ coronene $\left(\mathrm{C}_{24} \mathrm{H}_{12}\right)$, in addition to previously reported alcohol $(-\mathrm{OH})$ and ketone $(>\mathrm{C}=\mathrm{O})$ formation. This work represents the first experimental evidence that ice photochemistry may have contributed to the aromatics bearing carbon and nitrogen containing side groups that are detected in primitive meteorites and interplanetary dust particles. Furthermore, these results suggest that a wide range of modified PAHs should be expected in interstellar ices and materials that predated solar system formation. The implications of these results for interstellar and meteoritic chemistry are discussed.
\end{abstract}

Subject headings: astrobiology — astrochemistry — ISM: molecules — meteors, meteoroids — molecular processes - ultraviolet: ISM

\section{INTRODUCTION}

Polycyclic aromatic hydrocarbons (PAHs) are believed to be the most abundant and widespread class of organic compounds in the universe (Puget \& Leger 1989; Allamandola, Tielens, \& Barker 1989). PAHs are observed to be in the gas phase in a wide variety of interstellar environments, including protoplanetary and planetary nebulae, reflection nebulae, $\mathrm{H}$ II regions, and the diffuse interstellar medium (ISM; Allamandola, Hudgins, \& Sandford 1999). In dense molecular clouds where temperatures are low (10-20 K) most species condense onto refractory dust grains forming mixed molecular ice mantles. While $\mathrm{H}_{2} \mathrm{O}$ is the dominant species in these ice mantles, they also contain numerous other simple molecules (d'Hendecourt et al. 1999; Gibb et al. 2000; Ehrenfreund \& Charnley 2000). Aromatic C-H stretching and out-of-plane bending infrared (IR) absorptions measured toward a number of stars along lines of sight that pass through dense cloud material indicate the presence of PAHs (Sellgren et al. 1995; Brooke, Sellgren, \& Geballe 1999; Chiar et al. 2000; Bregman, Hayward, \& Sloan 2000; Bregman \& Temi 2001). Under dense cloud conditions these PAHs would be condensed into the ice mantles. Emission from PAHs has been tentatively reported in the coma of comet P/Halley (Moreels et al. 1994), so PAHs may also be present in cometary ices.

Aromatic compounds are common in carbonaceous chondrites (Basile, Middleditch, \& Oró 1984; Cronin, Pizzarello, \& Cruikshank 1988; Cronin \& Chang 1993) and interplanetary (cometary/asteroidal) dust particles (IDPs; Allamandola, Sandford, \& Wopenka 1987; Clemett et al. 1993). The aromatics in the Murchison meteorite carry deuterium (D) enrichments (Kerridge, Chang, \& Shipp 1987), and there is evidence that they may be one of the carriers of

\footnotetext{
${ }^{1}$ NASA Ames Research Center, Mail Stop 245-6, Moffett Field, CA 94035-1000; mbernstein@mail.arc.nasa.gov.

${ }^{2}$ Center for the Study of Life in the Universe, SETI Institute, Landings Drive, Mountain View, CA 94043.

${ }^{3}$ Department of Chemistry, Stanford University, Stanford, CA 943055080.
}

deuterium excess in IDPs (Messenger et al. 1995). These enrichments indicate that at least a portion of the aromatics in these objects have an interstellar origin (e.g., Sephton \& Gilmour 2000). We have previously discussed how deuterated aromatics can be produced in $\mathrm{D}_{2} \mathrm{O}$ ice photolysis experiments under interstellar conditions (Sandford et al. 2000; Sandford, Bernstein, \& Dworkin 2001).

Based on the evidence that aromatic compounds are commonly observed in interstellar space and in meteorites and should condense into interstellar grain mantles, we have investigated the energetic processing of PAHs in interstellar ice analogs to explore possible connections between interstellar and meteoritic PAHs. Mendoza-Gómez et al. (1995) had previously observed that IR features of the PAH coronene in pure $\mathrm{H}_{2} \mathrm{O}$ ice diminish when exposed to UV photolysis, suggesting that a reaction had occurred. We have shown that UV photolysis of coronene (and 10 other PAHs) in pure $\mathrm{H}_{2} \mathrm{O}$ ice results in hydrogen and oxygen atom addition, thereby forming quinones, alcohols, ethers, and $\mathrm{H}_{n}$-PAHs (Bernstein et al. 1999). In recent work we described the regiochemistry of the UV photolysis of the PAH naphthalene $\left(\mathrm{C}_{10} \mathrm{H}_{8}\right)$ in $\mathrm{H}_{2} \mathrm{O}$ ice, reporting the regiochemistry in preparation for comparison with meteoritic extracts (Bernstein et al. 2001). Most recently, studies of phenanthrene photooxidation and alkylation by Mahajan (2002) suggest a link between photochemical processes and meteoritic kerogen. Such laboratory experiments are consistent with detections of oxidized aromatics both as extractable meteoritic molecules (Krishnamurthy et al. 1992) and in meteoritic kerogen (Cody, Alexander, \& Tera 2002).

We report here an extension of our previous work to include the photochemistry of the PAH coronene $\left(\mathrm{C}_{24} \mathrm{H}_{12}\right)$ frozen in $15 \mathrm{~K}$ ices containing $\mathrm{O}_{2}, \mathrm{CO}_{2}, \mathrm{CO}, \mathrm{H}_{2} \mathrm{CO}$, $\mathrm{CH}_{3} \mathrm{OH}, \mathrm{CH}_{4}, \mathrm{HCN}$, and $\mathrm{NH}_{3}$. These molecules are representative of compounds found in interstellar ice mantles in dense clouds and toward protostars. For example, in ice around the high-mass protostar RAFGL 7009S the abundances of the single-carbon compounds relative to $\mathrm{H}_{2} \mathrm{O}$ are $\mathrm{CO}_{2} \approx 21 \%, \quad \mathrm{CO} \approx 15 \%, \mathrm{H}_{2} \mathrm{CO} \approx 3 \%, \mathrm{CH}_{3} \mathrm{OH} \approx 30 \%$, and $\mathrm{CH}_{4} \approx 4 \%$ (d'Hendecourt et al. 1999). All of these mol- 
ecules have also been observed at comparable concentrations toward W33A and other high-mass protostars (Gibb et al. 2000). In addition, $\mathrm{NH}_{3}$ was observed at the $10 \%$ level relative to $\mathrm{H}_{2} \mathrm{O}$ in NGC 7538 IRS 9 (Lacy et al. 1998), and at even higher levels toward GCS 3 (Chiar et al. 2000) and has since been observed toward a number of objects (Gibb, Whittet, \& Chiar 2001). Recent observations of intermediate-mass protostars suggest similar ice compositions (Thi 2002). All of the single-carbon compounds seen toward protostars have also been observed in the tails or comae of comets (Mumma 1997). Finally, it is reasonable to include HCN because it is commonly detected in cometary comae (Fink \& Hicks 1996), it is one of the more abundant gas-phase interstellar molecules known (Irvine 1996), and the majority of $\mathrm{HCN}$ in the dense ISM should be frozen onto grains. Thus, $\mathrm{H}_{2} \mathrm{O}$, all the listed single-carbon species, $\mathrm{NH}_{3}$, and $\mathrm{HCN}$ are reasonable starting materials for extraterrestrial ice experiments because they are among the most abundant molecules frozen onto grains in the dense ISM and in cometary comae. Finally, theoretical models have suggested that $\mathrm{O}_{2}$ may be present as well (Vandenbussche et al. 1999 and references therein).

A deeper understanding of the chemistry of PAHs bearing side groups is important for astrophysics because it may serve as an indicator of interstellar chemistry and a chronicle of planetary system formation from a molecular perspective. The identification of bona fide interstellar molecules (where synthesis from interstellar precursors can be excluded) in meteorites would be a demonstration that such species can survive solar system formation. The extent to which they have been modified would serve as a measure of nebular processing. Ultimately, specific knowledge of the locations of chemical groups and isotopes would be the most informative of the history of these species (Sandford et al. 2001).

Given the similarity between certain functionalized aromatic compounds in meteorites (such as quinones) and molecules ubiquitous in biochemistry (menaquinone, for example), and since large quantities of extraterrestrial material fell to Earth at the time of the origin of life, it has been suggested that the arrival of such molecules from space may have played a role in the evolution of biochemistry. Understanding how such molecules arise has relevance to the emerging field of astrobiology.

\section{EXPERIMENTAL}

The UV photolyses of coronene-containing ices were performed on a $15 \mathrm{~K}$ rotatable finger in an evacuated cryogenic sample chamber fitted with $\mathrm{H}_{2}$ UV lamp (Allamandola, Sandford, \& Valero 1988). In these experiments, the PAH coronene was vapor deposited from a borosilicate tube simultaneously with a gas mixture that condensed onto an Ni substrate (for mass spectrometry) or a CsI window (for IR spectroscopy) and into which the PAH was isolated (Hudgins \& Allamandola 1995). The gas mixtures typically were composed of 1-5 mbar of one of the following: $\mathrm{CO}_{2}$, $\mathrm{CO}, \mathrm{CH}_{3} \mathrm{OH}, \mathrm{CH}_{4}, \mathrm{NH}_{3}$, or $\mathrm{HCN}$ diluted in 20 mbar $\mathrm{H}_{2} \mathrm{O}$ vapor or 80 mbar Ar. Formaldehyde $\left(\mathrm{H}_{2} \mathrm{CO}\right)$ vapor pressures were much lower, well below a millibar (see below). Experiments were also performed with coronene in pure solid $\mathrm{CO}_{2}$ or $\mathrm{CO}$. The rate of deposition was estimated from the growth rate of fringes and absorption features in the IR spectra of samples deposited on a CsI substrate. $\mathrm{H}_{2} \mathrm{O}$ mix- tures were typically deposited at a rate that produced an ice layer $\sim 0.1 \mu \mathrm{m}$ thick after 30 minutes and typically had $\mathrm{H}_{2} \mathrm{O} / \mathrm{PAH}$ ratios of greater than 100 . The Ar mixtures were deposited at a rate that produced an ice layer $\sim 1.0 \mu \mathrm{m}$ thick after 30 minutes and had $\mathrm{Ar} / \mathrm{PAH}$ ratios of greater than 300 , so the PAHs were isolated from one another. The concentrations of the other molecules listed above were $5 \%-$ $25 \%$ relative to $\mathrm{H}_{2} \mathrm{O}$, consistent with IR astronomical observations. This vapor deposition technique produces intimately mixed ices with the $\mathrm{H}_{2} \mathrm{O}$ in a high-density amorphous form that is only observed at low temperatures and pressures and believed to be representative of $\mathrm{H}_{2} \mathrm{O}$-rich ices in interstellar molecular clouds (Jenniskens \& Blake 1994; Jenniskens et al. 1995). This resulted in ices where the PAHs were essentially isolated from one another and the ratio of $\mathrm{H}_{2} \mathrm{O}$ to the other molecules was typically $20 / 1$.

After deposition, samples were UV photolyzed using a microwave-powered, flowing hydrogen, discharge lamp (Warneck 1962) that produces $\sim 2 \times 10^{15}$ photons $\mathrm{cm}^{-2} \mathrm{~s}^{-1}$, the flux being nearly evenly divided between the Ly $\alpha$ line and a roughly $20 \mathrm{~nm}$ wide molecular transition centered at $160 \mathrm{~nm}$. Under such conditions, the time that elapses between photons arriving in the same molecular neighborhood is $\sim 13$ orders of magnitude longer than molecular relaxation times, so multiphoton processes are not relevant. The ice layers were all photolyzed for $\sim 30$ minutes $\left(\sim 4 \times 10^{18}\right.$ photons $\left.\mathrm{cm}^{-2}\right)$. This is a reasonable dose representing $\sim 500 \mathrm{yr}$ at the edge of a dense cloud and $\sim 1 \times 10^{5}$ $\mathrm{yr}$ at an optical depth of 5 within a dense molecular cloud, based on the interstellar radiation field and ignoring internal sources (Prasad \& Tarafdar 1983). Many ices were also photolyzed for $5 \mathrm{hr}$ to determine the extent of conversion that would be expected at higher UV flux.

After deposition and photolysis were complete, the ices were warmed at $\sim 2 \mathrm{~K}_{\text {minute }}{ }^{-1}$ under dynamic vacuum at $\sim 10^{-8}$ torr to room temperature. Under these experimental conditions the ice sublimes during warm up, leaving behind unreacted coronene and its photoproducts. At no point during this procedure does the ice melt, nor was the residual organic material exposed to any liquid. For cases in which the samples were prepared on an Ni substrate, the sample was removed from the vacuum system after it had reached room temperature. The residual organic material was then placed in the sample chamber of the microprobe laser desorption laser ionization mass spectrometer $\left(\mu \mathrm{L}^{2} \mathrm{MS}\right.$; located in the Chemistry Department, Stanford University; Clemett \& Zare 1997), and mass spectra were recorded of nonvolatile, PAH-related photoproducts remaining on the metal substrate.

The coronene was purchased from the Aldrich chemical company; control experiments indicate that it contains benzo[ghi]perylene $\left(\mathrm{C}_{20} \mathrm{H}_{12}\right)$ as a minor impurity. The water was purified with a Millipore Milli-Q water system to 18.2 $\mathrm{M} \Omega$. Methanol (Aldrich HPLC grade, 99.93\%) and water were freeze-pump-thawed three times prior to being transferred under vacuum into the glass bulb holding the matrix gases. The gases $\mathrm{O}_{2}, \mathrm{CO}_{2}, \mathrm{CO}, \mathrm{CH}_{4}$, and $\mathrm{NH}_{3}$ (Matheson $99 \%$ were transferred under vacuum into the glass bulb holding the matrix gases without any further purification. Formaldehyde $\left(\mathrm{H}_{2} \mathrm{CO}\right)$ was deposited into matrix as a monomer by drawing the vapor from above a sample of paraformaldehyde $\left(\mathrm{H}_{2} \mathrm{CO}\right.$ polymer, Aldrich). $\mathrm{HCN}$ was generated from the addition of concentrated $\mathrm{H}_{2} \mathrm{SO}_{4}$ (Poly Research Corporation) to KCN (Mallinckrodt) under vac- 
uum followed by vacuum distillation of the $\mathrm{HCN}$. The Ni substrate $(99.9 \%)$ was a $0.03 \mathrm{~mm}$ thick foil (Goodfellow). Additional information on the experimental procedures can be found on-line. ${ }^{4}$

\section{RESULTS}

We have already shown, based on IR spectral and $\mu \mathrm{L}^{2} \mathrm{MS}$ measurements, that the UV photolysis of PAHs in pure $\mathrm{H}_{2} \mathrm{O}$ at $15 \mathrm{~K}$ results primarily in oxidation of edge carbon atoms, yielding aromatic ketones and/or alcohols
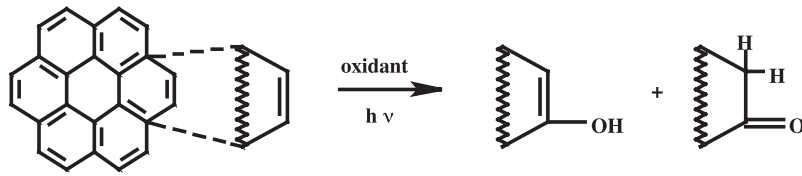

as well as some hydrogen atom addition (reduction) yielding PAHs bearing aliphatic bridges
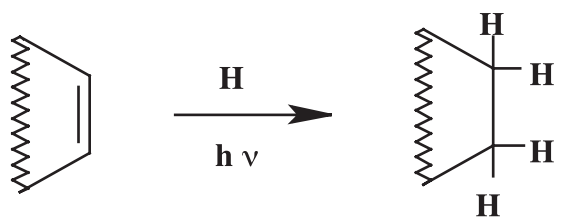

(Bernstein et al. 1999, 2001). We have since found that for the photolysis of coronene in any $\mathrm{H}_{2} \mathrm{O}$-rich ice, coronene oxidation is always the dominant reaction, and hydrogen atom addition always occurs, but not to the exclusion of other reactions. Similarly, the UV photolysis at $15 \mathrm{~K}$ of coronene in the presence of other molecules containing oxygen (such as $\mathrm{O}_{2}, \mathrm{CO}_{2}, \mathrm{CO}, \mathrm{H}_{2} \mathrm{CO}$, or $\mathrm{CH}_{3} \mathrm{OH}$ ) always resulted in some oxidation of the type shown in equation (1), and where protons are available $\left(\mathrm{H}_{2} \mathrm{CO}, \mathrm{CH}_{3} \mathrm{OH}, \mathrm{NH}_{3}, \mathrm{CH}_{4}\right.$, or $\mathrm{HCN})$ there is always some reduction, as shown in equation (2). In general, 10 minutes of UV photolysis $\left(<1 \times 10^{18} \mathrm{Ly} \alpha\right.$ photons) causes $\sim 15 \%$ oxidation of the coronene in $\mathrm{H}_{2} \mathrm{O}-$ rich ice. Preliminary evidence suggests that the rate of oxidation depends on the PAH, naphthalene being at least a factor of 10 slower to react than coronene (Bernstein et al. 2001).

The $\mu \mathrm{L}^{2} \mathrm{MS}$ of the residual organic material resulting from the UV photolysis of coronene in $\mathrm{CO}_{2}$ ice (Fig. 1) shows clusters of peaks of declining intensity with increasing mass. The groups of peaks at $M / Z=316,332,348$, and 364 amu correspond to the addition of one, two, three, and four oxygen atoms, respectively, to the coronene molecule. An elevated peak near 350 amu indicates the addition of two $\mathrm{H}$ atoms to the triply oxidized coronene. This spectrum also includes a small peak corresponding to a molecule with a mass of $344 \mathrm{amu}$. This is consistent with the addition of a molecule of $\mathrm{CO}_{2}$ to coronene to form an acid group<smiles>C1=CCCC=C1</smiles>
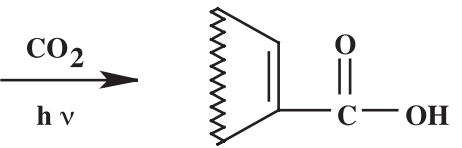

This peak has perhaps $1 \%$ of the area of the mass peak at $316 \mathrm{amu}$ (corresponding to the addition of a single oxygen atom) and thus represents a minor product under these conditions.

\footnotetext{
4 See http://www.astrochemistry.org.
}

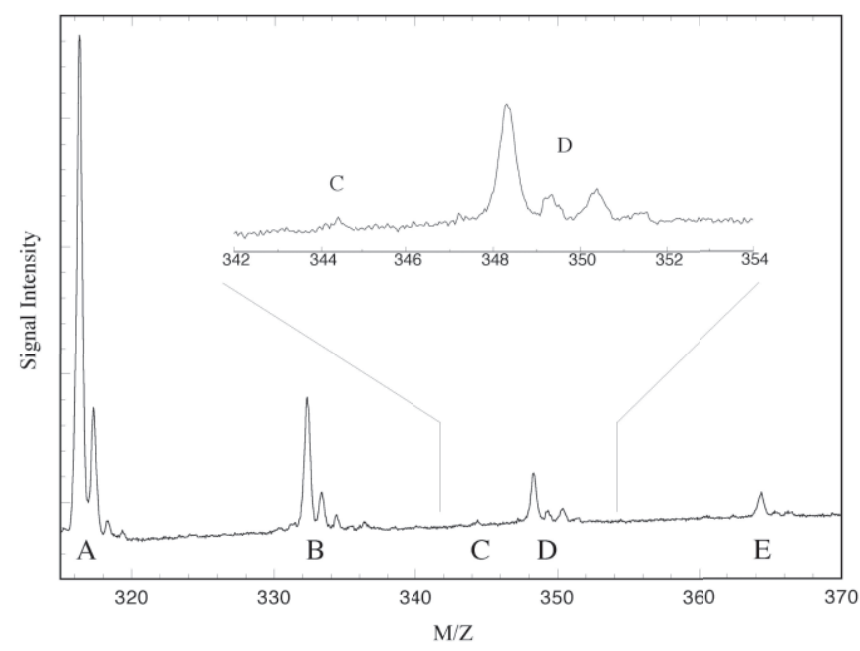

FIG. 1.- $\mu \mathrm{L}^{2} \mathrm{MS}$ spectrum of new molecules resulting from the $5 \mathrm{hr} \mathrm{UV}$ photolysis of coronene $\left(\mathrm{C}_{24} \mathrm{H}_{12}, 300 \mathrm{amu}\right)$ in $\mathrm{CO}_{2}$ ice $\left(\mathrm{CO}_{2} / \mathrm{PAH}>300\right)$ at $15 \mathrm{~K}$. The groups of peaks at 316 (A), 332 (B), 348 (D), and 364 (E) amu correspond to the addition of one, two, three, and four oxygen atoms, respectively, to the coronene molecule (eq. [1]). The area of peak $\mathrm{A}$ is approximately $1 \%$ that of unreacted coronene. The peak slightly above 350 amu (inset) indicates the addition of two $\mathrm{H}$ atoms (eq. [2]) to the triply oxidized coronene. The small peak at approximately $344 \mathrm{amu}(\mathrm{C})$ is consistent with the addition of $\mathrm{CO}_{2}$ to the coronene molecule resulting in a coronene carboxylic acid (see eq. [3]).

Furthermore, $\mu \mathrm{L}^{2} \mathrm{MS}$ (Fig. 2) demonstrates that the UV photolysis of our starting $\mathrm{PAH}$ in ices containing $\mathrm{NH}_{3}$ results in the addition of amino groups

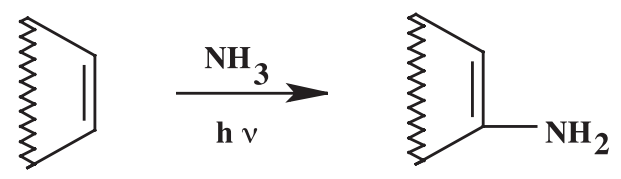

in ices containing $\mathrm{CH}_{4}$ results in the addition of methyl groups

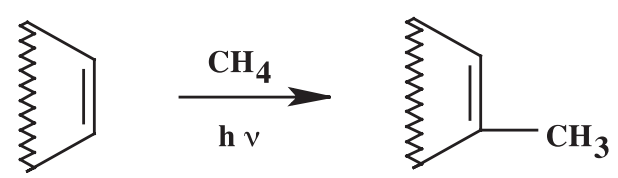

and in ices containing $\mathrm{CH}_{3} \mathrm{OH}$ results in the addition of methoxy groups to the coronene skeleton. In the case of $\mathrm{CH}_{3} \mathrm{OH}$ the mass spectral analyses show the addition of a single oxygen atom (eq. [1]; Fig. 2), a single methyl group (eq. [5]; Fig. 2), and the addition of two atoms or groups. Usually peaks for the addition of two groups or atoms are much smaller than for one; for example, compare peaks A and B in Figure 1, or look at the top two traces in Figure 2. For the photolysis of coronene in methanol, however, peaks corresponding to single-atom addition (Fig. 2, the peaks centered around 316) are not much larger than those for two atoms (Fig. 2, the peaks around 332), suggesting the preferential addition of two heavy atoms simultaneously, perhaps as part of a single moiety. The mass peaks for this double addition are ambiguous, being compatible with the addition of either a methoxy $\left(-\mathrm{OCH}_{3}\right)$ or a methylene alcohol $\left(-\mathrm{CH}_{2} \mathrm{OH}\right)$ group (or a mixture of both).

However, we can distinguish between these two functional groups based on the reactivity of the alcohol group. 


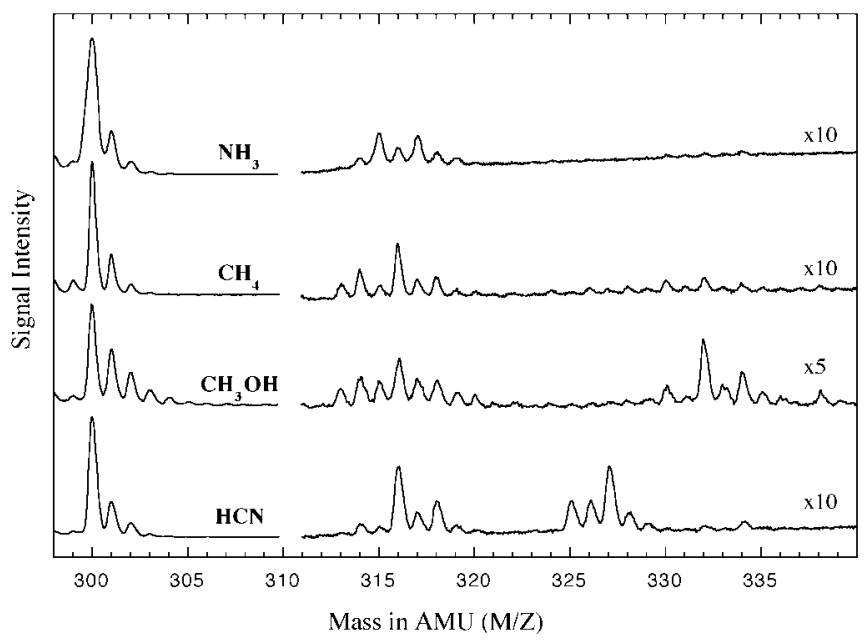

FIG. 2. $-\mu \mathrm{L}^{2} \mathrm{MS}$ spectra of organic material from the UV photolyses of coronene $\left(\mathrm{C}_{24} \mathrm{H}_{12}, 300 \mathrm{amu}\right)$ in ices with $\mathrm{H}_{2} \mathrm{O}$ and either $\mathrm{NH}_{3}, \mathrm{CH}_{4}$, $\mathrm{CH}_{3} \mathrm{OH}$, or $\mathrm{HCN}$ at $15 \mathrm{~K}$. The large peaks at 300-301 amu correspond to unreacted coronene (and its ${ }^{13} \mathrm{C}$ isomer). The peaks from 302 to 306 correspond to $\mathrm{H}_{n}$-coronenes and their fragments. The envelopes of peaks centered near 316 correspond to the addition of a side group containing only one oxygen (eq. [1]), nitrogen (eq. [4]), or carbon (eq. [5]) to the coronene molecule. The ensembles of peaks centered near 332 indicate coronenes bearing two such side groups and, in the case of $\mathrm{CH}_{3} \mathrm{OH}$, coronene methyl ether (eq. [6]). In the bottom trace the peaks centered around 327 indicate $\mathrm{CN}$ addition (eq. [7]). See text for details.

Treatment of this residual organic material in $\mathrm{D}_{2} \mathrm{O}$ failed to change the mass of the 330 peak. If an alcohol group had been present, the molecule would gain mass via exchange of an $\mathrm{H}$ for a D, and the peak would be expected to shift upward. Similarly, after treatment with bistrimethylsilylacetimide the mass spectrum did not show a peak for the corresponding trimethylsilyl-enol-ether. We have used both of these tests in the past to identify a coronene alcohol (Bernstein et al. 1999). These results suggest that most of the signal at $330 \mathrm{M} / Z$ derives from the methyl ether $\left(-\mathrm{OCH}_{3}\right)$, as seen in equation (6):
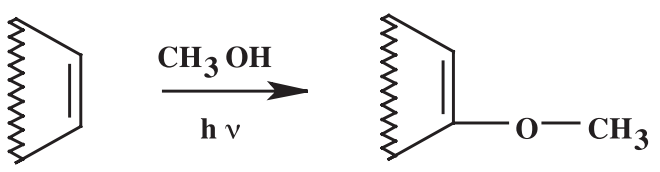

Finally, the UV photolysis of coronene in HCN-containing ices results in a suite of products. The peak in the mass spectrum at $325 \mathrm{amu}$ corresponds to the replacement of a hydrogen atom on coronene with a nitrile $(-\mathrm{CN})$ or isonitrile $(-\mathrm{NC})$ group
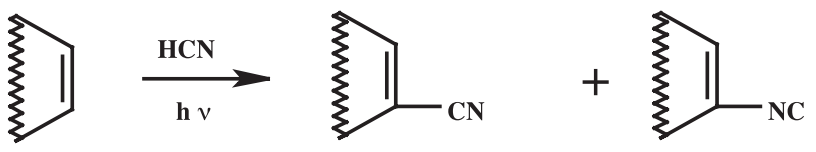

(Fig. 2). This is consistent with IR spectra of residual organic materials remaining after photolysis and warm-up of coronene $/ \mathrm{Ar} / \mathrm{HCN}$ experiments that include new nitrile and isonitrile stretching features. In addition, there is an even larger peak at $327 \mathrm{amu}$, corresponding to the addition of $\mathrm{C}, \mathrm{N}$, and two hydrogen atoms. This mass peak is suggestive of an $\mathrm{H}_{n}$-PAH structure, i.e., bearing an aliphatic bridge
( $-\mathrm{CH}_{2}-\mathrm{CH}_{2}-$; eq. [2]), in addition to a nitrile (or isonitrile). New aliphatic $\mathrm{C}-\mathrm{H}$ stretching features (in addition to that indicative of a nitrile) in the IR spectra of the residual material are consistent with this assignment.

Control experiments performed in the absence of either coronene or photolysis did not produce any coronenerelated products. These experiments indicate that the products described here are formed only when ice and coronene are exposed together to UV photolysis. Thus, they are not the result of contamination or other, nonphotolytic reaction processes. We did not see any evidence of ring (skeleton) breaking.

\section{DISCUSSION AND IMPLICATIONS}

Exposure of mixed molecular ices containing coronene to moderate UV photolysis produces new hydrogen, carbon, nitrogen, and oxygen bonds to coronene edge carbons, while control experiments in the absence of radiation (or coronene) do not. This demonstrates that the photolysis of PAHs in mixed molecular ices can lead to new and varied aromatic molecules.

In this study we reported only the reactions of the fully condensed PAH molecule coronene $\left(\mathrm{C}_{24} \mathrm{H}_{12}\right)$. We chose coronene because all of its external carbon atoms are equivalent, so a coronene bearing a single functional group (i.e., $-\mathrm{NH}_{2},-\mathrm{CH}_{3}$, etc.) has only one possible isomer. As a result of this symmetry, there was no need to determine where on the molecule the new moieties were located. However, preliminary work with other PAHs (Bernstein et al. 1999; Mahajan 2002) suggests that the reactions presented here are representative of the photochemistry of other PAHs in mixed molecular ices as well.

In our first study on the oxidation of PAHs in pure solid $\mathrm{H}_{2} \mathrm{O}$ (Bernstein et al. 1999) we noted that our results were consistent with the reactions proceeding via a PAH cation intermediate, and subsequent computational chemical studies have more fully explored this hypothesis (Ricca \& Bauschlicher 2000). In this study we have not performed any experiments exploring the dependence of these reactions on PAH structure, temperature, or radiation wavelength and as a result cannot address the reaction mechanism(s) responsible for these new products.

\subsection{Implications for Extraterrestrial Ices}

The oxidized coronenes were the most abundant products in all our photolysis experiments containing $\mathrm{H}_{2} \mathrm{O}$ and in most ices where oxygen was present in any form. These results suggest that aromatic alcohols and ketones will be the dominant products of PAH-ice photolysis in the solar system and in the ISM, where many ices are $\mathrm{H}_{2} \mathrm{O}$-rich. In addition, nonpolar interstellar ices (Sandford et al. 1988; Tielens et al. 1991; Ehrenfreund et al. 1997; Ehrenfreund \& Charnley 2000 and references therein) dominated by $\mathrm{CO}_{2}$ and/or CO will also act as oxidants in the presence of UV photons. Similarly, throughout the solar system where $\mathrm{H}_{2} \mathrm{O}$-rich ices are common and in other $\mathrm{CO}_{2}$ - or CO-containing planetary ices, such as the Martian polar cap, which contains substantial amounts of $\mathrm{CO}_{2}$ (Schmitt, de Bergh, \& Festou 1998), we expect that the action of UV radiation will cause oxidation of aromatics.

However, even in the presence of $\mathrm{H}_{2} \mathrm{O}$, UV-induced reactions between PAHs and other species do occur, forming 
new carbon - hydrogen, carbon - carbon, carbon - oxygen, oxygen, and carbon - nitrogen bonds. This suggests that in the neighborhood of protostars where there is radiation and high abundances of methanol (d'Hendecourt et al. 1999; Gibb et al. 2001) aromatics bearing methoxy and methyl moieties will be formed. The same products probably also form in solar system environments where ices contain methanol, such as on comets and icy planetesimals (Cruikshank et al. 1998b). Methyl groups should form in environments where methane is mixed with nitrogen, such as on Triton and Pluto (Cruikshank et al. 1998a). Similarly, amino groups should be formed where $\mathrm{NH}_{3}$ is present (Lacy et al. 1998; Chiar et al. 2000; Gibb et al. 2001). Given the molecular complexity of interstellar ices, it seems likely that an ensemble of aromatics including all these functional groups will readily form in most dense/protostellar cloud regions.

\subsection{Interstellar Aromatics in Meteorites}

Because dense clouds are the sites of star formation, modified aromatics bearing hydroxy, keto, amino, methyl, cyano, methoxy, and acid side groups should be part of the suite of organic molecules that are incorporated into forming planetary systems. Thus, these molecules should be present even before nebular and parent body processes begin to enrich the chemistry of the nascent cloud.

The kinds of molecules seen in meteorites are consistent with this proposed interstellar chemistry. For example, it has been shown that meteorites contain extractable aromatic molecules functionalized with ketone $(>\mathrm{C}=\mathrm{O}$; Krishnamurthy et al. 1992), aldehyde ( $-\mathrm{CH}=\mathrm{O}$; Sephton \& Gilmour 2001), acid (- $\mathrm{CO}_{2} \mathrm{H}$; Sephton, Pillinger, \& Gilmour 2001), and alkyl ( $-\mathrm{CH}_{3}$; Cronin et al. 1988) groups. Furthermore, evidence from degradation analyses (Hayatsu et al. 1980; Komiya, Shimoyama, \& Harada 1993; Sephton, Pillinger, \& Gilmour 1999) and nuclear magnetic resonance studies (Gardinier et al. 2000; Cody et al. 2002) of meteoritic macromolecular material suggest that it also contains such functional groups. Similarly, two-step laser mass spectra of IDPs are consistent with alkyl- and nitrogen-containing functional groups attached to aromatics (Clemett et al. 1993). While such side groups presumably could have added to the aromatics during a solar system process, the results presented here demonstrate that at least some chemical modification and augmentation to the basic PAH skeleton probably predated solar system formation.

This suggestion is consistent with $\mathrm{D}$ enrichments of many meteoritic molecules suggesting that they, or their precursors, originated in the ISM where temperatures are very low and molecules can become D-enriched. For example, polar hydrocarbon fractions in primitive meteorites (where oxidized aromatics are found) are considerably enriched in D (Kerridge et al. 1987). We have recently shown that the same UV photochemistry that modifies PAHs in ice can also explain their D enrichment (Sandford et al. 2000, 2001). Thus, any links between oxidation and $\mathrm{D}$ enrichment would suggest that the oxidation may have occurred in a low-temperature, D-enriched interstellar environment.
Although these reactions proceed in the laboratory and are consistent with analyses of extraterrestrial materials, ice photochemistry is, presumably, not the only way to produce such molecules. Other circumstellar, interstellar, and nebular processes could account for them as well. And even if ice photochemistry does make such molecules, subsequent nebular processing must modify many of them. For example, it is reasonable to suppose that parent body aqueous alteration strips off less stable side groups or replaces them. For example, it is well known that heating aromatics in liquid water can remove $-\mathrm{HCO}$, replace $-\mathrm{NH}_{2}$ with $-\mathrm{OH}$, and convert $-\mathrm{CN}$ to $-\mathrm{CO}_{2} \mathrm{H}$ (March 1985). Nevertheless, it seems likely that some of the substituted aromatics in meteorites resulted from interstellar ice photochemistry.

Finally, the presence of functionalized aromatic materials in meteorites may be of astrobiological interest because some of these molecules are essential for important processes in living systems. Thus, their delivery to the early Earth by extraterrestrial sources may have played a role in the evolution of the Earth's biosphere.

\section{CONCLUSIONS}

UV photolysis of the PAH coronene $\left(\mathrm{C}_{24} \mathrm{H}_{12}\right)$ in mixed molecular ices at $15 \mathrm{~K}$ adds side groups to the $\mathrm{PAH}$ including amino $\left(-\mathrm{NH}_{2}\right)$, methyl $\left(-\mathrm{CH}_{3}\right)$, methoxy $\left(-\mathrm{OCH}_{3}\right)$, cyano $(-\mathrm{CN})$, isocyano $(-\mathrm{NC})$, and acid $\left(-\mathrm{CO}_{2} \mathrm{H}\right)$ groups, in addition to previously reported hydroxy $(-\mathrm{OH})$, ketone $(\mathrm{C}=\mathrm{O})$, and bridging ether $(\mathrm{C}-\mathrm{O}-\mathrm{C})$ groups.

The efficiency of addition of these functional groups depends on the radiation dose and ice composition, but all reactions except acid formation were observed even after short lab doses equivalent to modest dense molecular cloud exposures.

The formation of PAHs with such side groups seems very likely in interstellar (and solar system) environments where observations indicate the presence of ice that contains simple molecules such as methane, methanol, ammonia, etc.

This same interstellar photolysis process is expected to lead to D enrichment of the aromatics. Thus, if a significant fraction of the aromatics in meteorites and IDPs have been processed in this manner, deuterium enrichment in aromatics should correlate with functionalization $\left(-\mathrm{CH}_{3}\right.$, $-\mathrm{OH},-\mathrm{CO}_{2} \mathrm{H},-\mathrm{CH}_{2} \mathrm{CH}_{2}-$, etc.).

This photochemical process should occur not only in the ISM but also on the surface of icy solar system bodies and planetary polar caps where aromatics in ices are exposed to radiation.

This work was supported by NASA grants 344-37-44-01 (Origins of Solar Systems), 344-38-12-04 (Exobiology), 344-50-92-02 (Astrobiology), and NAG 5-7208 (Cosmochemistry). The authors gratefully acknowledge useful discussions with George Cody III, excellent technical support from R. Walker, and helpful comments from an anonymous reviewer.

\section{REFERENCES}

Allamandola, L. J., Hudgins, D. M., \& Sandford, S. A. 1999, ApJ, 511, L115

Allamandola, L. J., Sandford, S., \& Valero, A. G. 1988, Icarus, 76, 225

Allamandola, L. J., Sandford, S. A., \& Wopenka, B. 1987, Science, 237, 56

Allamandola, L. J., Tielens, A. G. G. M., \& Barker, J. R. 1989, ApJS, 71, 733
Basile, B. P., Middleditch, B. S., \& Oró, J. 1984, Geochim. Cosmochim. Acta, 5,211

Bernstein, M. P., Dworkin, J. P., Sandford, S. A., \& Allamandola, L. J. 2001, Meteoritics Planet. Sci., 36, 351

Bernstein, M. P., Sandford, S. A., Allamandola, L. J., Gillette, J. S., Clemett, S. J., \& Zare, R. N. 1999, Science, 283, 1135 
Bregman, J. D., Hayward, T. L., \& Sloan, G. C. 2000, ApJ, 544, L75

Bregman, J. D., \& Temi, P. 2001, ApJ, 554, 126

Brooke, T. Y., Sellgren, K., \& Geballe, T. R. 1999, ApJ, 517, 883

Chiar, J. E., Tielens, A. G. G. M., Whittet, D. C. B., Schutte, W. A Boogert, A. C. A., Lutz, D., van Dishoeck, E. F., \& Bernstein, M. P. 2000, ApJ, 537, 749

Clemett, S., Maechling, C., Zare, R., Swan, P., \& Walker, R. 1993, Science, 262,721

Clemett, S. J., \& Zare, R. N. 1997, in Molecules in Astrophysics: Probes and Processes, ed. E. F. van Dishoek (Dordrecht: IAU), 305

Cody, G. D., III, Alexander, C. M. O'd., \& Tera, F. 2002, Geochim. Cosmochim. Acta, 66, 1851

Cronin, J. R., \& Chang, S. 1993, in The Chemistry of Life's Origins, ed. J. Greenberg, C. Mendoza-Gómez, \& V. Pirronello (Dordrecht: Kluwer), 209

Cronin, J. R., Pizzarello, S., \& Cruikshank, D. P. 1988, in Meteorites and the Early Solar System, ed. J. F. Kerridge \& M. S. Matthews (Tuscon: Univ. Arizona Press), 857

Cruikshank, D. P., et al. 1998a, Icarus, 135, 389

Cruikshank, D. P., Rousch, T. L., Owen, T. C., Quirico, E., \& de Bergh, C. 1998b, in Solar System Ices, ed. B. Schmitt, C. de Bergh, \& M. Festou (Dordrecht: Kluwer), 655

d'Hendecourt, L., et al. 1999, in The Universe as Seen by ISO, Vol. II ed. P. Cox \& M. F. Kessler (ESA SP-427; Noordwijk: ESA), 589

Ehrenfreund, P., Boogert, A. C. A., Gerakines, P. A., Tielens, A. G. G. M., \& van Dishoeck, E. F. 1997, A\&A, 328, 649

Ehrenfreund, P. \& Charnley, S. B. 2000, ARA\&A, 38, 427

Fink, U., \& Hicks, M. D. 1996, ApJ, 459, 729

Gardinier, A., Derenne, S., Robert, F., Behar, F., Largeau, C., \& Maquet, J. 2000, Earth Planet. Sci. Lett., 184, 9

Gibb, E. L., et al. 2000, ApJ, 536, 347

Gibb, E. L., Whittet, D. C. B., \& Chiar, J. E. 2001, ApJ, 558, 702

Hayatsu, R., Winans, R. E., Scott, R. G., McBeth, R. L., Moore, L. P., \& Studier, M. H. 1980, Science, 207, 1202

Hudgins, D. M., \& Allamandola, L. J. 1995, J. Phys. Chem., 99, 3033

Irvine, W. M. 1996, Nature, 383, 418

Jenniskens, P., \& Blake, D. F. 1994, Science, 265, 753

Jenniskens, P., Blake, D. F., Wilson, M. A., \& Pohorille, A. 1995, ApJ, 455, 389

Kerridge, J. F., Chang, S., \& Shipp, R. 1987, Geochim. Cosmochim. Acta, 51,2527
Komiya, M., Shimoyama, A., \& Harada, K. 1993, Geochim. Cosmochim. Acta, 57, 907

Krishnamurthy, R., Epstein, S., Cronin, J., Pizzarello, S., \& Yuen, G. 1992, Geochim. Cosmochim. Acta, 56, 4045

Lacy, J. H., Faraji, H., Sandford, S. A., \& Allamandola, L. J. 1998, ApJ, 501, L105

Mahajan, T. B. 2002, Ph.D thesis, Stanford Univ.

March, J. 1985, Advanced Organic Chemistry: Reactions, Mechanisms, \& Structure (3d ed.; New York: Wiley)

Mendoza-Gómez, C. X., de Groot, M. S., \& Greenberg, J. M. 1995, A\&A, 295,479

Messenger, S., Clemett, S. J., Keller, L. P., Thomas, K. L., Chillier, X. D. F., \& Zare, R. N. 1995, Meteoritics Planet. Sci., 30, 546

Moreels, G., Clairemidi, J., Hermine, P., Brechignac, P., \& Rousselot, P. 1994, A\&A, 282, 643

Mumma, M. J. 1997, in IAU Colloq. 161, Astronomical and Biochemical Origins and the Search for Life in the Universe, ed. C. B. Cosmovici, S. Bowyer, \& D. Werthimer (Bologne: Editrice Compositore), 121

Prasad, S. S., \& Tarafdar, S. P. 1983, ApJ, 267, 603

Puget, J. L., \& Leger, A. 1989, ARA\&A, 27, 161

Ricca, A., \& Bauschlicher, C. W., Jr. 2000, Chem. Phys. Lett., 328, 396

Sandford, S. A., Allamandola, L. J., Tielens, A. G. G. M., \& Valero, G. 1988, ApJ, 329, 498

Sandford, S. A., Bernstein, M. P., Allamandola, L. J., Gillette, J. S., \& Zare, R. N. 2000, ApJ, 538, 691

Sandford, S. A., Bernstein, M. P., \& Dworkin, J. P. 2001, Meteoritics Planet. Sci., 36, 1117

Schmitt, B., de Bergh, C., \& Festou, M. 1998, Solar System Ices (Dordrecht: Kluwer)

Sellgren, K., Brooke, T. Y., Smith, R. G., \& Geballe, T. R. 1995, ApJ, 449, L69

Sephton, M. A., \& Gilmour, I. 2000, ApJ, 540, 588 2001, Planet. Space Sci., 49, 465

Sephton, M. A., Pillinger, C. T., \& Gilmour, I. 1999, Planet. Space Sci., 47, 181

2001, Planet. Space Sci., 49, 101

Thi, W.-F. 2002, Ph.D. thesis, Leiden Univ.

Tielens, A. G. G. M., Tokunaga, A. T., Geballe, T. R., \& Baas, F. 1991, ApJ, 381, 181

Vandenbussche, B., et al. 1999, A\&A, 346, L57

Warneck, P. 1962, Appl. Opt., 1, 721 